\title{
AdRTVP-1-Transduced Prostate Cancer Cell-Based Vaccine
}

National Cancer Institute

\section{Source}

National Cancer Institute. AdRTVP-1-Transduced Prostate Cancer Cell-Based Vaccine.

NCI Thesaurus. Code C64785.

A cell-based vaccine comprised of prostate cancer cells transduced with an adenoviral vector encoding human RTVP-1 (AdRTVP-1), with potential antineoplastic and immunostimulating activities. RTVP-1, also referred to as glioma pathogenesis-related protein 1 (GLIP1), is down-regulated in prostate tumors. Regulated by tumor suppressor p53, the expression of RTVP-1 functions as a tumor suppressor, and is abundant in normal human prostate epithelial cells as well as in differentiated macrophages.

Administration of this vaccine leads to an induction of apoptosis through the expression of RTVP-1 and results in a reduction in cellular proliferation in prostate cancer cells. In addition, this cancer-cell based vaccine may induce a cytotoxic T lymphocyte (CT L) response against prostate specific tumor associated antigens, resulting in an immunemediated prostate cancer cell death. Furthermore, RTVP-1 stimulates CTL and natural killer (NK) cell activities. 